\title{
KONTESTASI FIGURAL DALAM INDUSTRI BUDAYA YOGA Oleh:
}

\author{
Kadek Hemamalini \\ Dosen urusan Penerangan Agama \\ Sekolah Tinggi Agama Hindu Dharma Nusantara Jakarta \\ Email : kadekhema@gmail.com
}

\begin{abstract}
:
Yoga became a popular culture can not be separated from the influence of cultural industries that then bring a new face in yoga practice. Yoga is known today is yoga asanas which besides beneficial to health is also full of entertainment nuance as an implication of postmodern society lifestyle and also the implications of the role of media in society. So it is said yoga practice is now a propan yoga practice, away from sacred values like the teachings that should be in yoga itself. This phenomenon raises the awareness of certain groups of people to show and restore the true teachings of yoga through yoga-yoga mass done in the areas of the shrine by taking time yoga as it should. So no doubt this condition raises social stratification that appears in the community in a form of contestation of yoga practices.
\end{abstract}

Keywords: contestation, yoga, cultural industry

\section{ABSTRAK}

Yoga menjadi budaya popular tidak dipisahkan dari pengaruh budaya industri yang kemudian membawa wajah baru dalam praktik yoga. Yoga saat ini dikenal sebagai yoga asana yang disamping bermanfaat untuk kesehatan juga penuh dengan nuansa pertunjukan sebagai sebuah implikasi dari gaya hidup masyarakat postmodern dan juga implikasi dari pengaruh media di masyarakat. Dikatakan bahwa praktik yoga yang dilakukan sekarang ini adalah latihan yang bersifat profane, sudah jauh dari nilai-nilai kesakralan sebagaimana semestinya di dalam pelajaran yoga. Fenomena ini memunculkan kesadaran dari berbagai kelompok orang untuk menunjukkan dan mengembalikan ajaran yang benar dengan melaksanakan yoga di areal tempat suci. Oleh karena itu tidak diragukan bahwa kondisi ini akan memunculkan stratifikasi social dalam bentuk kontestasi praktik yoga.

Kata Kunci: kontestasi, yoga, budaya industry

\section{PENDAHULUAN}

Yoga sudah menjadi budaya populer dewasa ini. Kepopuleran yoga membawa perubahan terhadap wajah yoga itu sendiri. Hal ini tidak bisa dihindari mengingat pengaruh budaya postmodern yang berimbas pada gaya hidup masyarakatnya. Belum lagi karena pengaruh media membawa yoga menjadi sebuah budaya yang dipraktikkan di seluruh dunia. Melihat hal ini, praktek yoga memiliki pangsa yang besar dan luas dilihat dari sudut pandang kapitalis sehingga menjadikan yoga sebagai sebuah komoditas dalam industri budaya yang dampaknya membawa perubahan terhadap praktek yoga tersebut.

Namun perubahan yoga yang terjadi dewasa ini membawa kegelisahan bagi masyarakat yang mengatasnakan yoga sebagai sebuah ajaran yang bersifat sakral yang merupakan sebuah ajaran kelepasan dalam filsafat Hindu sehingga mulai muncul gerakan-gerakan yang dapat dikatakan sebagai gerakan memurnikan ajaran yoga. Tidak hanya itu mulai muncul kelompok-kelompok masyarakat yang mengajak dan melakukan praktek yoga sesuai seperti yang diajarkan 
seharusnya dalam yoga itu sendiri. Sehingga tanpa dapat dihindari lagi dewasa ini muncul stratifikasi terkait dalam praktek yoga tersebut.

\section{PEMBAHASAN}

\subsection{Gaya Hidup sebagai Pendorong Industri Budaya}

Yoga menjadi tren saat ini tidak terlepas dari konsep "keterbukaan" (openness) kehidupan sosial masa kini, seperti yang diuraikan Chaney, bahwa perkembangan gaya hidup dan perubahan struktural modernitas saling terhubung melalui reflektivitas institusional: 'karena 'keterbukaan' (openness) kehidupan sosial masa kini, pluralisasi konteks tindakan dan aneka ragam 'otoritas', pilihan gaya hidup semakin penting dalam penyusunan identitas-diri dan aktivitas keseharian. Masyarakat disuguhi semua informasi tentang yoga baik melalui iklan-iklan media cetak, elektronik, dan spanduk-spanduk kursus yoga yang banyak bertebaran di tempat-tempat strategis, belum lagi iklan-iklan di tempat gym and fitness yang menyelenggarakan tentang yoga.

Pengenalan tentang yoga juga dilakukan dalam format workshop yoga yang sering diselenggarakan oleh studio-studio yoga sendiri untuk memperkenalkan studio yoga nya dan tentu saja dengan tujuan untuk menjaring member. Workshop-workshop ini mengajak masyarakat tidak hanya untuk langsung mempraktekkan yoga tetapi juga mendapatkan teori yang memadai tentang yoga dan tentu saja mendapatkan sertifikat kepesertaan mengikuti workshop.

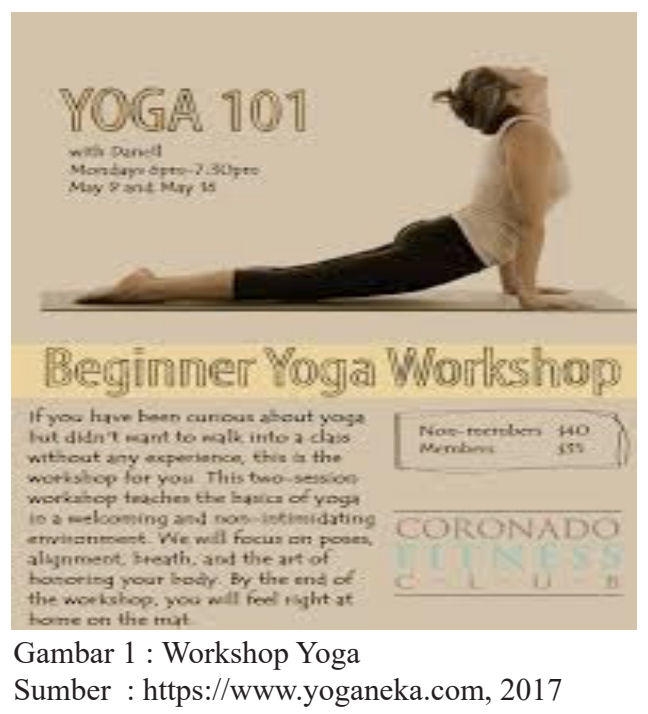

Hal ini menurut Chaney (2008) sebagai bentuk refleksi yang sangat kreatif didalam memunculkan pasar sehingga menjadi sebuah tren yang akhirnya memunculkan gaya hidup. Hal ini sejalan dengan pandangan Gidden yang menyatakan bahwa diperlukan cara-cara menggunakan sumber daya simbolik konsumsi massa yang diubah menjadi objek-objek atau praktik-praktik yang kasat mata yang merupakan metafor bagi mereka sendiri.

Menurut Utama (2016), bahwa minat masyarakat dewasa ini terutama masyarakat kelas menengah keatas semakin tinggi dalam mengikuti praktik yoga. Karena praktik yoga asana tidak hanya dipahami sebagai ajaran untuk mencapai kesehatan fisik dan batin melainkan juga dimaknai sebagai aktivitas simbolik untuk menunjukkan identitas diri mereka di masyarakat. Dengan kata lain motivasi dalam mengikuti yoga memang cenderung pada hal-hal yang pragmatis, yang menurut Kotler sebagai suatu bentuk ekspresi dari masyarakat tersebut dalam aktivitas, minat dan opininya.

Gaya hidup masyarakat tersebut berimplikasi terhadap daya konsumsinya. Masyarakat tidak hanya mengkonsumsi sesuatu berdasarkan nilai guna, akan tetapi berubah menjadi consumer, yakni mengkonsumsi sesuatu selain untuk menghabiskan nilai guna juga karena muatan nilai simbolik (status sosial, gengsi, dan prestise) pencitraan diri agar penampilan enak ditonton oleh orang lain (Piliang, 1998), sehingga pasar dengan mekanisme produksi dan pencitraan media memainkan peran penting menjadikan Yoga Asana sebagai gaya hidup kelas menengah kota.

Banyaknya selebriti Indonesia yang memposting foto-foto mereka di media sosial saat melakukan yoga seperti: Marshanda, Luna Maya, Andien, dan masih banyak selebriti lainnya semakin mendongkrak minat masyarakat terhadap yoga. Selebriti merupakan seorang publik figur yang segala aktivitas, gaya hidupnya menjadi perhatian dan sorotan bagi masyarakat dan tak jarang menjadi contoh atau panutan. Masyarakat ini kadang berusaha meniru gaya hidup selebriti kesayangan mereka. Sehingga dalam hal ini, selebriti memiliki peran dalam menjadikan yoga 
semakin populer. Belum lagi artis yang menjadi instruktur yoga seperti Anjasmara, tentunya memiliki nilai jual yang lebih tinggi untuk menarik minat masyarakat karena masyarakat pasti merasa penasaran ingin melihat tokoh selebriti itu terlebih dulu sebelum melihat praktik yoganya.

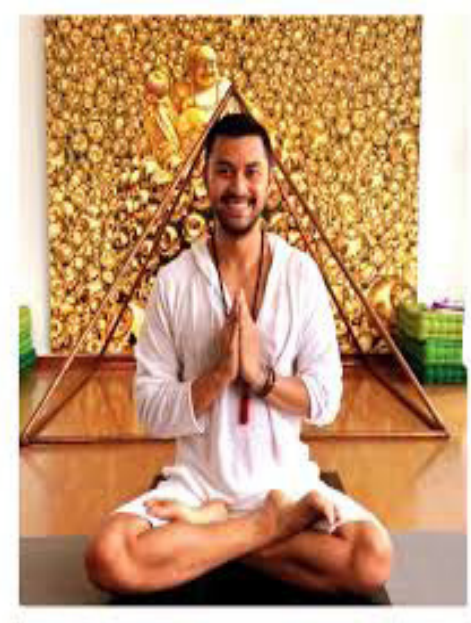

Gambar 2 Artis Yoga Anjasmara Sumber : https://www.google.co.id/ search, 2017

Tren yoga yang dikalangan artis dewasa ini membawa juga perubahan gaya hidup dikalangan artis lainnya yang mana imbasnya pun akan terjadi pada masyarakat luas. Seperti Acro Yoga menjadi tren saat ini dikalangan selebriti Indonesia, mereka seakan-akan berlomba-lomba menunjukkan diri akan kebisaan mereka mempraktikkan posepose sulit dalam Acro Yoga. Media sosial seperti Instagram, Youtube, menjadi sarana yang paling cepat untuk memamerkan sekaligus sebagai media publikasi pencitraan selebriti tersebut.

\subsection{Stratifikasi Sosial pada Dua Kelompok Yoga}

Yoga yang sudah begitu populer membawa implikasi tersendiri akan kepopulerannya. Nyatanya yoga sebagai budaya populer memunculkan suatu konflik dalam stratifikasi masyarakat urban yang memunculkan fenomena kultural. Sebagai bagian dari proses-proses sosial, dalam banyak kasus dijumpai bahwa konflik sosial tidak berlangsung secara serta-merta. Dalam hal ini, berkembangnya yoga sebagai budaya populer membawa dampak seperti apa yang disebut Collins sebagai munculnya stratifikasi sosial.
Muncul kesenjangan pemahaman antara kelompok yang memiliki sumber daya dan kekuasaan dengan kelompok yang memiliki sumber daya terbatas. Menurut Collins, hal ini terjadi bahwa kelompok yang memiliki sumber daya dan berkuasa dapat memaksakan sistem gagasan mereka terhadap seluruh masyarakat, sedangkan kelompok tanpa sumber daya mempunyai sistem gagasan yang dipaksakan terhadap mereka (Ritzer \& Goodman dalam Collins (2011:164).

Praktik yoga dibawah naungan kapitalisme menjadi sebuah industri budaya yang besar. Bermunculan praktek-praktek yoga massal yang sarat akan nuansa enternain yang menarik sekaligus menghibur. Praktik yoga pun dilakukan di tempat-tempat wisata yang bagus dan terkenal yang tujuannya adalah untuk mengakomodir kenyamanan peserta yoga nya.

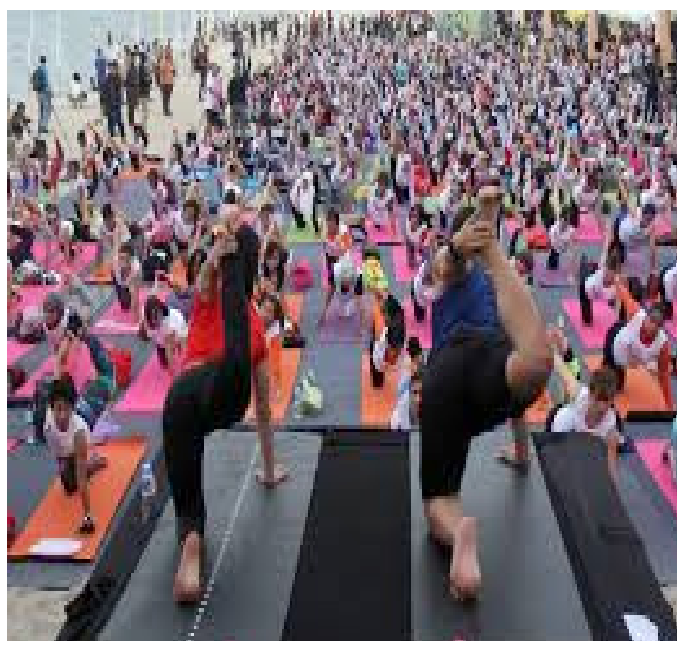

Gambar 3 : Yoga in the Dark - Ancol

Sumber : Web Celebrity Fitness, 2017

Di Bali sendiri muncul kegelisahan terkait dengan komodifikasi yoga dewasa ini, sehingga mulai muncul apa yang disebut dengan pemurnian terhadap ajaran yoga. Yoga yang dewasa ini dipraktekkan dianggap mulai menyimpang dari ajaran yoga sesungguhnya. Menurut hasil penelitian Utama (2016), di Ubud terdapat satu kelompok Yoga yang disebut Yoga Barn yang diasuh oleh Putu Gede Suyoga. Dalam kelompok Yoga Barn ini mengharuskan setiap sisya nya untuk melakukan proses pewintenan. Pewintenan merupakan suatu bentuk penyucian dalam ajaran 
Hindu yang bertujuan untuk membersihkan dan menyucikan manusia baik secara fisik maupun batin.

Penyucian ini dilakukan karena yoga merupakan ajaran suci yang sakral sehingga harus dijaga kesucian dan kesakralannya termasuk dimensi spiritualitasnya . Kelompok ini melakukannya dengan tetap menyertakan mantramantra suci atau Gayatri Mantram sebagai esensi yang sangatpenting untuk membangkitkan kembali energi Ketuhanan didalam diri manusia (Utama, 2016). Beberapa dijumpai kasus-kasus konflik sosial yang bertipe "constructive social conflict" seperti yang terjadi di Amerika. Di Amerika muncul gerakan yang menamakan dirinya Hindu American Foundation (HAF) yang mengikarkan diri untuk mengambil kembali gerakan yoga ke asalnya dengan menyebutnya sebagai "Take Back Yoga" movement. Dikatakan bahwa praktisi yoga dewasa ini terlalu menekankan pada asana dan pranayama sebagai satu kesatuan tetapi melupakan enam aspek lainnya dari Asthangga Yoga. Berdasarkan hal itu, India kemudian mematenkan sekitar 1500 pose yoga agar tidak diklaim oleh Barat. Dalam http://www,merdeka.com (11 Agustus 2015), pemerintah India memutuskan mematenkan 1500 pose senam yoga dalam dokumentasi video untuk menghalangi upaya negara Barat mengklaim hak cipta pose-pose yoga.

\subsection{Kontestasi Praktek Yoga sebagai Budaya Populer}

Konflik sosial yang berlangsung antar kelompok (inter-group social conflict) di ruang masyarakat sipil dapat menyangkut krisis pluralitas-sosio-budaya dan bernuansa identitas sosial. Dalam konflik bernuansa etno-komunal, sangat tampak nyata adanya para pihak yang membawa atribut identitas ideologi, identitas antar-keagamaan, identitas kelompok atau juga perbedaan mazhab pada agama yang sama (konflik sektarian), serta perbedaan asal-usul atau keturunan sebagai pembeda utama kelompok yang saling menggugat, pelancaran klaim, atas persoalan yang disengketakan.

Konflik-konflik antar komunitas (communal conflicts), yang bisa disebabkan berbagai faktor, seperti: eksistensi identitas budaya komunitas dan faktor sumber daya kehidupan (sources of sustenance). Konflik komunal seringkali bisa berkembang menjadi konflik teritorial jika setiap identitas kelompok melekat juga identitas kawasan. Muncul kesenjangan pemahaman antara kelompok yang memiliki sumber daya dan kekuasaan dengan kelompok yang memiliki sumber daya terbatas. Menurut Collins, hal ini terjadi bahwa kelompok yang memiliki sumber daya dan berkuasa dapat memaksakan sistem gagasan mereka terhadap seluruh masyarakat, sedangkan kelompok tanpa sumber daya mempunyai sistem gagasan yang dipaksakan terhadap mereka (Ritzer \& Goodman dalam Collins (2011:164).

Bukan kekerasan individu, tetapi situasi kekerasan-ini adalah apa yang mikro-sosial teori logis jelaskan. Collins mencari kontur situasi, yang membentuk emosi dan tindakan individu-individu yang berada di dalamnya. Ini palsu yang mengarah untuk mencari jenis kekerasan individu, konstan di seluruh situasi. Kondisi ini akan memunculkan apa yang Collins sebut sebagai 'speed of yang diberikan para pihak atas ketidaksepahaman yang terbentuk di kalangan berkonflik. Seperti apa yang diuraikan Collins bahwa dampak dari stratifikasi sosial yang terjadi akibat perbedaan ideologi terkait dengan praktek yoga memunculkan suatu gerakan dari golongan yang menurut Collins disebut sebagai kelompok sosial yang didominasi yaitu gerakan sosial damai (peaceful collective action) yang berlangsung berupa aksi penentangan, yang dapat berlangsung dalam bentuk: "aksi korektif".

Gerakan-gerakan ini penulis cermati dalam bentuk mulai muncullnya kegiatan-kegiatan yoga yang dilakukan oleh umat Hindu dan ditujukkan untuk kepentingan umat Hindu sendiri baik dalam bentuk yoga massal maupun grup kelas-kelas yoga yang lebih kecil. Di Jakarta sendiri mulai gencar dilakukannya yoga massal. Baik yang dilakukan secara kontinyu maupun yang dilakukan secara temporer, namun yang penting disini adalah penggagasnya. Penggagas dari yoga massal ini adalah umat Hindu dengan target jangkauan peserta yoga adalah umat Hindu sendiri. Namun tidak menutup kemungkinan peserta dari non Hindu yang penting kembali adalah penggagasnya 
dengan dominan pesertanya. Seperti yoga yang dilakukan di Pura Rempoa Jakarta Selatan. Yoga di Pura ini mulai aktif dilakukan dalam kurun waktu 10 bulan terakhir yang dilakukan setiap hari Minggu pukul 6 pagi di pelataran parkir pura.

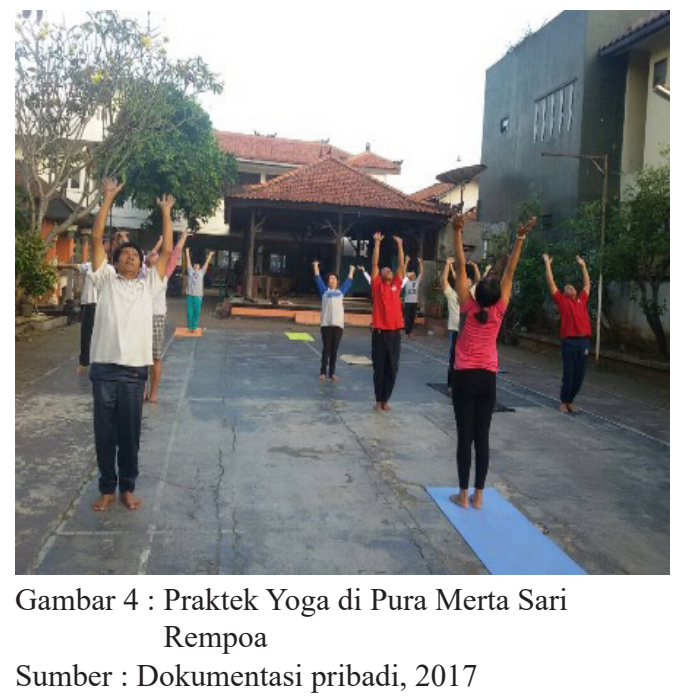

Penggagas sekaligus instruktur yoga nya adalah JMG I Wayan Ardana. Yoga yang mulai rutin dipraktekkan ini sebagai imbas dari keprihatinan beliau terkait dengan yoga modern dewasa ini. Hal yang ironis bahwa umat Hindu sendiri tidak sering bahkan ada yang tidak pernah sama sekali melakukan yoga sementara orang lain, umat lain beryoga bahkan hampir setiap hari, kita malah asing dengan ajaran kita sendiri. Yoga massal lain dilakukan pada tanggal 30 Juli 2017 di pelataran parkir Pura Aditya Jaya Rawamangun. Yoga ini diadakan dalam rangka pujawali pura Aditya Jaya yang ke-87 dan digagas oleh PHDI, WHDI dan SDHD Jakarta Timur.

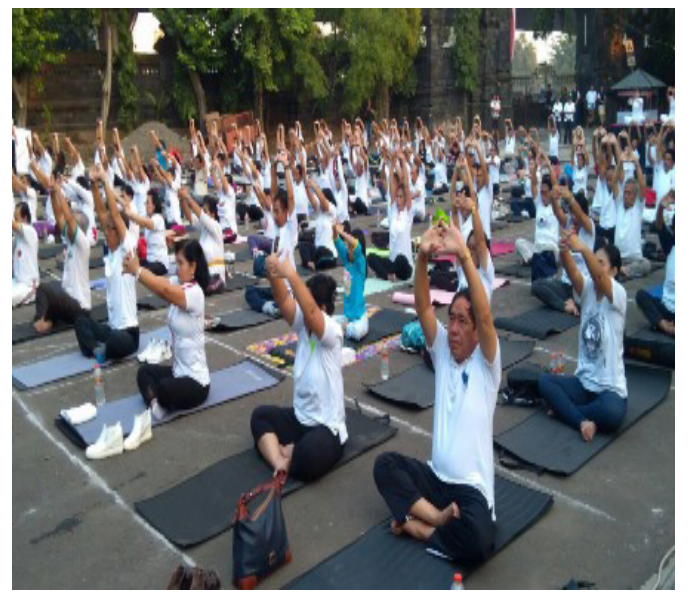

Gambar 5: Peserta praktek yoga di Pura Aditya Jaya Rawamangun

Sumber : Dokumentasi pribadi, 2017
Yoga massal ini diadakan sebagai rangkaian pujawali pura Aditya Jaya yang ke-87 dan mengusung tema "Olah Gerak Jasmani dan Spiritual”.

Yoga massal yang terbanyak diikuti oleh peserta Hindu adalah yoga massal di Cibubur yang diadakan pada tanggal 9 April 2017 yang diikuti oleh sekitar 1500 umat Hindu sejabotabek. Bertempat di Bumi Perkemahan dan Graha Wisata Pramuka Cibubur, Kempa 1 Garuda Cibubur, Jakarta Timur, Minggu 9 April 2017, yang di selenggarakan oleh Panitia bersama PHDI Pusat (Parisada Hindu Dharma Indonesia) dan Panitia Nasional Perayaan Hari Raya Nyepi Tahun Baru Saka 1939, yang di ketuai oleh Ni Nyoman Rai Sumawati. Kegiatan ini mengambil tema : "Melalui Yoga dan Penyuluhan Anti Narkoba Kita Tingkatkan Kualitas SDM dan Hubungan yang Harmonis Antar Umat Beragama”. (Dirjen Bimas Hindu Press).

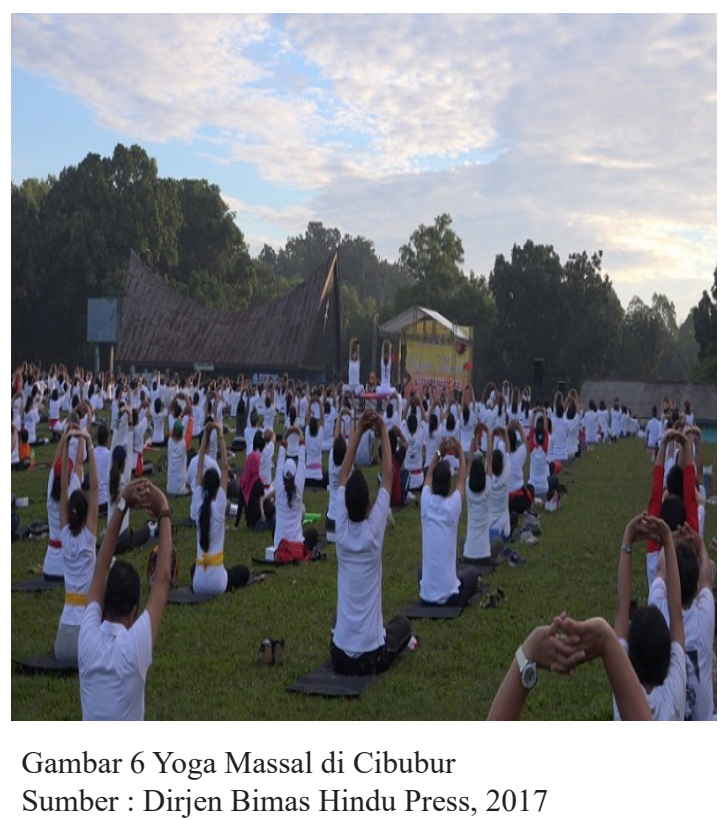

Sumber : http://www.bintang.com/celeb

Sumber $:$ http://www,merdeka.com

Sumber : SvaraHindu.com Tidak hanya di seputaran Jakarta muncul gerakan-gerakan yoga massal yang diprakarsai oleh umat Hindu, di beberapa daerah muncul kegiatan yang sama seperti yang dilakukan di Yogjakarta. Yoga massal yang dilakukan sebagai wujud nyata 
umat Hindu untuk mengaplikasikan ajaran Veda dengan memasyarakatkan yoga kepada semua umat Hindu. Walaupun yoga merupakan ajaran yang sangat universal dan banyak diminati oleh semua kalangan tanpa membedakan suku ataupun agamanya bahkan yoga sudah menjadi bagian hidup bagi orang-orang barat sehingga menjadi suatu yang ironis apabila orang Hindu sendiri yang tidak memahami dan mengaplikasikan ajaran yoga tersebut. Inilah yang menjadi renungan dan pemacu semangat untuk terus memasyarakatkan ajaran yoga.

Seperti yang diadakan oleh Bimas Hindu Kanwil Kementerian Agama D.I.Yogyakarta selaku dari pemerintah bekerja sama dengan Panitia Perayaan Hari Raya Nyepi Tahun Saka 1938/2016 Masehi selaku dari Lembaga Parisadha D.I.Yogyakarta, mengawali memasyarakat gerakan yoga kepada umat Hindu D.I.Yogyakarta dengan melaksanakan kegiatan pembinaa Yoga Asana angkatan I (pertama). Walaupun kegiatan yoga massal ini dilakukan sebagai rangkaian untuk menyambut Hari Raya Nyepi Tahun Saka 1938/2016 Masehi, terdapat pesan yang jelas yang melatarbelakangi kegiatan yoga massal tersebut, yang mengambil tema tentang filsafat yoga. Pemberian pemahaman tentang filsafat yoga ini disampaikan pada para peserta yoga asanas agar semua tahu dan paham tentang ajaran yang terkandung dalam yoga. Sehingga akhirnya semua umat Hindu menjadi paham bahwa yoga merupakan ajaran Hindu yang sudah ada ribuan tahun yang lalu yang sudah diajarkan oleh Maharsi Patanjali.

Dan penekanan pada penyampaian yang diberikan kepada seluruh umat Hindu yang ada di D.I.Yogyakarta dalam acara Yoga Asanas di Pura Waikunta Wyomantara bahwa yoga merupakan warisan Hindu yang setidaknya sebagai seorang pewaris harus tahu dan paham tentang yoga sebagai milik Hindu. Oleh sebab itu, sebagai umat Hindu dapat melestarikan yoga sebagai warisan Hindu yang perlu di kembangkan untuk umat Hindu secara umum di Indonesia dan secara khususnya di D.I.Yogyakarta.

Pesan tersebut secara simbolik menyatakan bahwa yoga walaupun merupakan ajaran filsafat Hindu sudah menjadi milik dunia. Sehingga yoga yang mendunia seolah-olah menutupi ajaran yoga sebagaimana yang diajarkan dalam Hindu itu sendiri. UNHI Denpasar juga mengadakan kegiatan yang sama yang bertajuk "Yoga massal ini bertajuk Citta Wretti Nirodha". Kegiatan ini membawa pesan untuk menunjukkan praktek yoga sesungguhnya pengendalian diri menuju keseimbangan dan keharmonisan.

Melihat fenomena perkembangan budaya yoga dewasa ini yang didukung oleh budaya konsumsi dan gaya hidup masyarakat posmodern khususnya kaum urbannya menjadikan yoga sebagai budaya populer yang mengarah pada sebuah industri budaya. Industri budaya sedang melibatkan diri dalam bentuk indoktrinasi ideology yang canggih dengan menggunakan hiburan untuk mempermanis penindasan sambil menggerogoti standar kebudayaan dengan tujuan menekan setiap bentuk ekspresi yang menentang tatanan yang ada (Sugihartati dalam Adorno, 2014 : 28-29).

Darmayasa seorang spiritualis sekaligus praktisi yoga mengemukakan pendapatnya tentang perkembangan yoga dewasa ini:

““Kebanyakan orang mempraktikkan yoga sebagai olah raga dan lain-lain manfaat badani. Jarang orang mempraktikkan yoga sebagai yoga. Ketika orang mempraktikkan yoga sebagai yoga mereka akan mempraktikkan meditasi sampai tingkat samadhi, tingkat puncak dari yoga".

Seperti yang dipaparkan juga oleh Svami Visnu Devananda yang merupakan salah seorang yogi yang memperkenalkan yoga ke dunia Barat termasuk Indonesia, pernah berkomentar mengenai masalah ini, bahwa sangat disayangkan apabila seseorang hanya melakukan praktik Hatha Yoga tetapi meninggalkan praktik Raja Yoga (meditasi) karena dengan bermeditasi ia akan mendapatkan manfaat yang tertinggi dari segala usahanya dalam Hatha Yoga. Begitu pula sebaliknya, disayangkan apabila seseorang hanya melakukan Raja Yoga tanpa melakukan Hatha Yoga karena dalam praktik Hatha Yoga ia akan mempelajari teknik pengendalian nafas 
(pranayama) dan asana yang sangat bermanfaat untuk mengendalikan pikiran dan tubuh pada saat bermeditasi (Suwantana, 2016:78).

Munculnya berbagai opini tersebut menunjukkan bahwa yoga sebagai sebuah budaya populer memunculkan konflik dikalangan umat Hindu sendiri sebagai pemilik ajaran yoga. Disatu sisi keinginan untuk mengenalkan yoga sebagai suatu cara untuk mencapai tujuan spiritual tertinggi yang dibawa oleh para maha Rsi ke Barat, namun di sisi lain setelah yoga tersebut mendunia munculnya ketakutan akan hilangnya jati diri atau akar dari ajaran yoga itu sendiri karena perkembangan yoga dewasa ini.

Agama secara sosiologis merupakan unsur dari budaya masyarakat, maka mudah dipahami bahwa dengan adanya pergeseran nilai-nilai dalam masyarakat, eksistensi agama termasuk bagian yang terkena imbasnya. Proses globalisasi yang gencar merasuki segala segi kehidupan mau tak mau dirasakan pengaruhnya oleh agama. Dalam permainan kuasa inilah agama ikut bersaing baik dengan sistem nilai agama lain maupun unsur budaya lainnya (Sudiarja, 2006:34). Dalam hal ini Hindu sebagai agama tempat ajaran yoga berasal merasa berkewajiban untuk menempatkan kembali ajaran yoga sebagaimana seharusnya.

\section{PENUTUP}

Gaya hidup masyarakat dewasa ini secara tidak langsung mempengaruhi woekshopmunculnya industri budaya dalam praktek yoga. Ditambah lagi dengan dukungan media membawa praktek yoga menjadi sebuah budaya komersil yang memunculkan stratifkasi budaya terhadap asal budaya yoga itu sendiri dan kontestasi dari dua kelompok yoga tidak terelakkan lagi kemunculannya sebagai dampak dari perubahan yang terjadi dalam praktik yoga itu sendiri.

\section{Daftar Pustaka}

Barker, Chris. 2000. Cultural Studies. Yogyakarta: Kreasi Wacana

Chaney, David. 2006. Lifestyles: Sebuah Pengantar Komprehensif. Yogajakarta : Jalasutra
Featherstone, Mike.2008. Posmodernisme dan Budaya Konsumen. Yogyakarta : Pustaka Pelajar.

George Ritzer \& Douglas J., Goodman, 2011. Teori Sosiologi Modern Yogyakarta: Kreasi Wacana,

Ihalauw, J.O.I John. 2008. Konstruksi Teori. Jakarta. PT. Gramedia Widiasarana Indonesia.

Ritzer, George dan Goodman, Doudglas. 2011. Teori Sosiologi Modern. Jakarta : Kencana Prenada Media Group.

Strinati, Dominic.2016. Popular Culture Pengantar Menuju Teori Budaya Populer. Yogyakarta: Narasi

Sugihartati, Rahma.2014. Perkembangan Masyarakat Informasi \& Teori Sosial Kontemporer. Jakarta : Kencana

Suwantana, I Gede. 2016. Perkembangan Yoga Di Seluruh Dunia : Prosiding Seminar Nasional Kemanfaatan Latihan Fisik Dalam Meningkatkan Kesehatan Jasmani dan Rohani Menuju Kesempurnaan Hidup. Denpasar : IHDN. . 2015. Teori dan Metode Psikologi Hindu. Denapasar : UNHI Press.

Utama, Budi I Wayan. 2016. Yoga Sebagai Life Style. Denpasar : UNHI

Sumber-Online :

Sumber : https://www.google.co.id/search

Sumber : http://www.yoganeka.com 